\title{
Control de los niños con cardiopatía congénita en Atención Primaria
}

\author{
B. Herranz Jordán \\ Pediatra. CS El Abajón de Las Rozas. Madrid. España.
}

Rev Pediatr Aten Primaria. 2009; I :639-55

Benjamin Herranz Jordán, bherranz@telefonica.net

\begin{abstract}
Resumen
Las cardiopatías congénitas son frecuentes, pero la mayoría son leves y no requieren cuidados pediátricos especiales. En España y otros países desarrollados, las que los necesitan son corregidas pronto, se limita su período sintomático y generalmente presentan pocas secuelas. Por todo ello, el seguimiento de los niños con cardiopatía congénita en Atención Primaria ocasiona poca carga asistencial. Sin embargo, para algunos pacientes, como los que tienen defectos más complejos, los cuidados pediátricos son importantes. En este trabajo se revisan los conocimientos actuales al respecto.
\end{abstract}

Palabras clave: Cardiopatías congénitas, Atención Primaria.

\section{Abstract}

Congenital heart diseases are frequent, but most of them are minor and do not require special pediatric care. In Spain and other developed countries those who need it are corrected soon, limiting the symptom's period and usually have with few sequelae. For these reasons, the follow up of children with congenital heart diseases suppose little work load for the primary care units. Nevertheless, pediatric care is important for some patients, like those who have more complex defects. The current knowledge about this subject is reviewed in this paper.

Key words: Congenital heart disease, Primary Care.

Las cardiopatías congénitas no son enfermedades raras. Su incidencia es próxima al $1 \%$ de los recién nacidos vi$\operatorname{vos}^{1}$, pero los estudios de incidencia clásicos no consideran por definición como cardiopatías congénitas, ni por lo tanto buscan de forma activa, varias anoma- lías leves y frecuentes, como la válvula aórtica bicúspide, la comunicación interventricular muscular pequeña, la comunicación interauricular pequeña o el ductus del neonato. Tampoco incluyen otras cardiopatías no malformativas pero que en ocasiones son congénitas, co-

El autor declara no presentar posibles conflictos de intereses en relación con la preparación y publicación de este artículo.

Este texto corresponde parcialmente al presentado en el $58 .{ }^{\circ}$ Congreso de la Asociación Española de Pediatría, en junio de 2009 en Zaragoza. 
mo arritmias o miocardiopatías. Cuando se han considerado y buscado activamente todas éstas, la incidencia puede llegar al 7,5\%². La válvula aórtica bicúspide por sí sola afecta al 1-2\% de la población. Las cardiopatías adquiridas son mucho menos frecuentes que las congénitas, pero es necesario recordar su existencia y variedad (valvulopatías, arritmias, miocardiopatías, miocarditis, pericarditis, enfermedades autoinmunes y sistémicas con repercusión cardíaca, etc.). Pese a su frecuencia, la carga asistencial que supone el seguimiento de niños con cardiopatías para el pediatra de Atención Primaria (AP) en la actualidad es pequeña. Esto se explica porque la mayoría de las congénitas son leves y porque en España los pacientes que lo necesitan son corregidos pronto y bien. Por el contrario, en los servicios de cardiología de adultos, los pacientes con cardiopatías congénitas suponen una carga asistencial mayor que hace décadas debido a la mayor supervivencia de niños con cardiopatías complejas ${ }^{3}$.

Para el pediatra de AP, los conocimientos y habilidades prioritarios en cardiología son los que le permiten reconocer los síntomas y los signos de una cardiopatía. Su sospecha diagnóstica puede ser vital para un niño grave que no haya sido diagnosticado en el hospi- tal tras el parto (situación afortunadamente excepcional en España). En segundo lugar, el pediatra debe saber realizar un seguimiento adecuado de aquellos niños que lo necesiten. Algunos estudios llevados a cabo en otros países concluyeron que los médicos de AP se implicaban poco y descuidaban aspectos que les eran propios, tales como las vacunas o la prevención de las caries ${ }^{4}$. Sus conclusiones seguramente no son extrapolables a nuestro entorno, donde la mayor parte son atendidos por pediatras y no por médicos generales.

A fin de determinar la atención pediátrica que requieren los niños con cardiopatía, un esquema práctico consiste en clasificarlos en cuatro grupos:

\section{Cardiopatías leves}

Las más características son los pequeños cortocircuitos izquierda a derecha (a nivel ventricular, auricular o ductal), la estenosis pulmonar leve, la válvula aórtica bicúspide nada o levemente estenótica y el prolapso mitral sin insuficiencia mitral. En los informes, además del diagnóstico anatómico, el cardiólogo suele etiquetarlas como leves, banales o sin repercusión hemodinámica. No tienen ninguna repercusión sobre la salud del niño y su pronóstico es bueno: la gran mayoría de los cortocircuitos pe- 
queños se cerrarán solos en los primeros meses o años, y las demás cardiopatías de este grupo o no empeorarán, o lo harán muy lentamente (en décadas). La única causa de descompensación brusca e imprevisible es que sufran una endocarditis, lo cual es muy improbable. Por lo tanto, estos pacientes no precisan más revisiones pediátricas que las de un niño normal bien controlado. Un exceso de atención induce a pensar a la familia, y al propio niño cuando es mayor, que padece una enfermedad más grave. La mitad o más de los pacientes con cardiopatía pertenecen a este grupo.

\section{Cardiopatías asintomáticas, pero no leves}

Son niños que están asintomáticos (o escasamente sintomáticos) y que pueden permanecer así durante meses o años, pero que no tienen cardiopatías leves. El pronóstico sólo es bueno en algunos cortocircuitos que, aun no siendo inicialmente pequeños, pueden evolucionar al cierre espontáneo en los primeros años de vida. Los demás cortocircuitos y todas las demás cardiopatías de este grupo empeorarán y precisarán cirugía o cateterismo intervencionista en algún momento, generalmente en la infancia. El cardiólogo infantil los citará con intervalos entre los cuales prevé que no van a sufrir un empeoramiento significativo, pero en algunos se pueden programar revisiones pediátricas intermedias (por ejemplo, en un lactante con comunicación interventricular y curva ponderal escasa).

\section{Cardiopatías sintomáticas}

Este grupo está compuesto básicamente por lactantes con cardiopatías graves, que desarrollan síntomas en las primeras semanas o meses de vida. En ellos son muy necesarios los cuidados pediátricos que expondremos a continuación. Deben ser revisados tanto por el cardiólogo como por el pediatra con la periodicidad que requiera cada caso en particular. Para evaluar un posible empeoramiento es muy útil disponer de los informes de las revisiones del hospital $y$, si es posible, de un electrocardiograma y una radiografía de tórax previos con los que poder comparar.

\section{Arritmias}

El papel del pediatra de AP en el control de los niños con arritmias se puede resumir en no dar mayor importancia a las banales, controlar de manera discreta las demás y no administrar fármacos que puedan empeorarlas (figura 1). La cirugía cardíaca previa es un factor de gravedad en cualquier arritmia. 
Los niños que han sido operados o sometidos a cateterismo intervencionista y quedan con secuelas pueden ser igualmente clasificados en uno de los grupos previos, según la gravedad de éstas.

\section{Nutrición y crecimiento}

Los niños con cardiopatías congénitas pueden presentar fallo de medro o mal- nutrición (ver definiciones en la figura 2) y retraso del crecimiento por su lesión cardíaca, pero también por su asociación a síndromes malformativos, cromosomopatías, bajo peso en el nacimiento o prematuridad $^{5}$ (figura 3 ).

Las cardiopatías leves, como ya se ha indicado, no tienen ninguna repercusión sobre la nutrición o el crecimiento.

Figura 1. Arritmias: ¿qué podemos hacer en Atención Primaria?

\section{Las banales no necesitan seguimiento}

- PR largo, marcapasos migratorio, ritmo del seno coronario sin cardiopatía de base, extrasístoles auriculares o ventriculares "benignas"

\section{En las demás necesito:}

- Saber qué le puede pasar y qué puedo hacer si le pasa

- Resaltar en la historia fármacos peligrosos

- Guardar un ECG con la arritmia

Figura 2. Malnutrición y fallo de medro.

\section{Malnutrición: ingesta insuficiente de alimentos}

1. Carencia generalizada (desnutrición)

- Calórico-proteica

- Proteica

- Aguda: $I M C<P_{3-5}$ (adulto=18; 6 años=12), peso/talla $<P_{10}$

- Crónica: talla baja para su edad

2. Carencia específica, sintomática o no

\section{Fallo de medro: niño de hasta 2-3 años que}

1. Está muy delgado: $P$ eso $<\mathrm{P}_{3-5}$

2. O no engorda: $\Delta$ de peso $<$ de $2 D S$ en $2-3$ meses 
Las cardiopatías que repercuten por sí mismas sobre ellos se pueden dividir en dos grupos:

1. Cardiopatías congénitas que afectan desde las primeras semanas o meses de vida: son las que cursan con insuficiencia cardíaca congestiva precoz, especialmente si tienen: a) hipertensión pulmonar (por ejemplo, una comunicación interventricular grande o asociada a coartación aórtica) o b) cianosis por mezcla de sangre arterial y venosa (por ejemplo, una transposición de grandes arterias con comunicación interventricular) ${ }^{6}$. La desnutrición afecta inicialmente al peso $y$, si es grave y prolongada, también al crecimiento en longitud y al crecimiento cerebral (que se evalúa mediante el perímetro cefálico). Tras una corrección quirúrgica exitosa generalmente se observa una rápida recupe- ración del peso, que en pocos meses será normal para la edad (fenómeno de alcance o (atch-up). Sin embargo, en desnutriciones graves y prolongadas, la talla y el perímetro cefálico puede que no se recuperen por completo, y es posible que queden secuelas neurológicas permanentes. El tratamiento médico, incluido el nutricional, tiene como objetivo mantener en el mejor estado posible al enfermo hasta que sea operado. Cuanto más precoz es la cirugía, menor resulta la desnutrición?.

2. Cardiopatías congénitas que tienen una repercusión más tardía e irregular: se pueden dividir en tres grupos, por orden de mayor a menor repercusión $n^{6}$ :

- Cardiopatías cianosantes: cuando sobreviven años, se ve afectado primero el peso y luego la talla. En la

Figura 3. Causas de malnutrición en las cardiopatías.

Por la propia cardiopatía

- Menor ingesta: disnea, hipoxemia, hipotonía

- Regurgitaciones y vómitos

- Mayor consumo

- Infecciones intercurrentes

- Malabsorción

Por otros factores

- Prematuridad

- Síndromes 
actualidad sólo se observa en niños con cardiopatías cianosantes complejas que no pueden ser completamente corregidas, o en países pobres donde no son operados o lo son a una edad no adecuada. El alcance (catch-up) posquirúrgico en estos pacientes es irregular.

- Cortocircuitos izquierda a derecha moderados: son niños poco sintomáticos en los que a largo plazo se puede ver afectado el peso, pero rara vez la talla. Por motivos desconocidos, cortocircuitos hemodinámicamente similares afectan de manera desigual ${ }^{8}$.

- Lesiones obstructivas moderadas: en general son niños asintomáticos y no se ven afectados ni el peso ni la talla.

\section{Alimentación domiciliaria del lactante con cardiopatía}

1. Alimentación al pecho: se debe mantener el pecho mientras la ganancia ponderal sea adecuada. Puede ser a demanda en cardiopatías asintomáticas. En las sintomáticas no se aconseja pasar de las 3 horas de pausa. Se debe instruir a la madre para que deje descansar al lactante unos segundos si le nota jadeante o cianótico. Para evitar que regurgiten, es conveniente no moverlos ni cambiarles de pañal tras las tomas, y ponerlos a dormir discretamente semisentados (en decúbito supino o lateral). La posición semisentada también mejora la disnea si se tiene insuficiencia cardíaca.

2. Alimentación con biberón: su utilidad se basa en que permite medir el aporte y aumentar la densidad calórica de las tomas, pero no es cierto el tópico de que cueste menos trabajo que la succión del pecho materno, ya que se ha documentado lo contrario: se produce un mayor consumo de oxígeno con la succión del biberón que del pecho.

3. Alimentación con sonda: se recurre a la sonda nasogástrica cuando con el pecho o el biberón no ganan peso. Es aconsejable proseguir con pequeñas tomas para mantener el reflejo de succión. La sonda se coloca en el hospital y el niño debe permanecer ingresado hasta que se determine la pauta idónea y la familia esté bien instruida. Es raro que un niño con una cardiopatía que precisa ser alimentado por sonda sea dado de alta. Con leche materna o fórmula de dilución normal (densidad calórica aproximada de 0,6-0,7 kcal/ml), la cantidad de agua precisada para suministrar las calorías necesarias para que un lactante desnutrido no siga perdiendo o recupere peso (en torno a $150 \mathrm{kcal} / \mathrm{kg} / \mathrm{día}$ ) es 
inviable para la situación hemodinámica en la que se encuentran estos pacientes, por lo que resulta necesario aumentar la densidad calórica con un suplemento de dextrinomaltosa y triglicéridos de cadena media; ambos se añaden en una proporción calórica similar. Se suele llegar hasta $1,5 \mathrm{kcal} / \mathrm{ml}$, vigilando que la osmolaridad urinaria no sobrepase los 400 $\mathrm{mOsml} / \mathrm{l}$ y que no ocasione vómitos o esteatorrea.
Se deben controlar el peso con la periodicidad que necesite cada caso, así como la longitud y el perímetro cefálico cada 1 ó 2 meses. La circunferencia del brazo puede ser también de utilidad. Hay que tener presente que pueden ganar peso en poco tiempo por el empeoramiento de la insuficiencia cardíaca (retención hídrica) y perderlo por los diuréticos. La osmolaridad en la orina es útil y fácil de determinar. Hay que limi-

Tabla I. Tipos de preparados nutricionales comerciales

\begin{tabular}{|c|c|c|}
\hline Denominación & Descripción & Presentaciones \\
\hline Dieta polimérica & $\begin{array}{l}\text { Son alimentos completos, isoosmolares } \\
\text { y sin gluten. } \\
\text { Hay dietas poliméricas para dos grupos } \\
\text { de edad: niños (1-10 años) y adultos. } \\
\text { También hay diferencias entre } \\
\text { productos de un mismo grupo: } \\
\text { densidad calórica (1-1,5 kcal/ml), tipos } \\
\text { de hidratos de carbono, de grasa } \\
\text { y de proteínas, cantidad de fibra. }\end{array}$ & Líquidos, de sabores diversos \\
\hline $\begin{array}{l}\text { Suplemento } \\
\text { nutricional }\end{array}$ & $\begin{array}{l}\text { Contienen los } 3 \text { principios inmediatos } \\
\text { y algunos otros nutrientes, pero no son } \\
\text { alimentos completos } \\
\text { El límite inferior de edad para poder } \\
\text { usarlos está entre } 1 \text { y } 3 \text { años } \\
\text { (lo especifica el fabricante) } \\
\text { Como en el caso anterior, hay } \\
\text { diferencias entre diversos productos }\end{array}$ & $\begin{array}{l}\text { En polvo para disolver, o en cremas } \\
\text { y barritas para consumir } \\
\text { directamente, de sabores diversos }\end{array}$ \\
\hline $\begin{array}{l}\text { Módulo o dieta } \\
\text { modular }\end{array}$ & $\begin{array}{l}\text { Contienen un solo principio inmediato } \\
\text { (hidratos de carbono, lípidos } \\
\text { o proteínas) o bien una asociación } \\
\text { de hidratos de carbono y lípidos }\end{array}$ & Líquidos y en polvo \\
\hline
\end{tabular}


tar todo lo posible las extracciones de sangre, ya que estos niños precisan buenas vías venosas para sus múltiples ingresos hospitalarios.

\section{Alimentación domiciliaria del niño mayor con cardiopatía}

En un niño o adolescente con cardiopatía significativa y peso bajo puede haber una relación causal basada en una nutrición insuficiente. Se debe procurar aumentar la ingesta calórica con alimentos que le resulten apetitosos y añadir a las comidas habituales una cantidad mayor de aceite de oliva o maíz, mantequilla, salsas, azúcar, cacao, etc. También se puede suplementar la dieta con algún preparado comercial que le guste. En la tabla I se aclara la terminología de los tipos disponibles ${ }^{10}$.

\section{Prevención de la anemia ferropénica}

Los niños con cardiopatías cianosantes requieren una mayor cantidad de hemoglobina para atenuar la hipoxia tisular, por lo que en ellos cifras normales de hemoglobina y hematocrito indican anemia. La causa más probable es la carencia de hierro, y el mejor parámetro para evaluarla es el volumen corpuscular medio por debajo de $73^{11}$. Para prevenir la anemia por carencia de hierro en niños con cardiopatías cianosantes es una práctica ha- bitual la administración de suplementos orales, bien continuos en dosis bajas, bien discontinuos en dosis mayores. En adultos con insuficiencia cardíaca se ha demostrado que la anemia empeora el pronóstico, pero su causa es multifactorial (hemodilución, hiporregeneración medular, carencial y por pérdidas) ${ }^{12}$.

\section{Restricción hidrosalina}

A los pacientes con riesgo o clara insuficiencia cardíaca se les aconseja no añadir sal en las comidas y evitar los alimentos salados. En su condición de niños se pueden tolerar pequeños excesos puntuales (por ejemplo, en un cumpleaños). Las necesidades de agua dependen en buena medida de la ingesta de sal, por lo que si ésta se controla no es preciso restringir el agua, salvo en casos de insuficiencia cardíaca grave.

\section{Ejercicio físico y descanso $0^{13,14}$}

Los niños con cardiopatías leves pueden realizar todo tipo de esfuerzos. En las cardiopatías sintomáticas y en algunas asintomáticas (por ejemplo, en una estenosis aórtica moderada) se aconseja evitar los esfuerzos bruscos o extenuantes, pero incluso en estos pacientes hay que promover el ejercicio recreativo hasta el límite en que sea bien tolerado, ya que ello mejorará su capacidad física y la inte- 
gración con otros niños. Por el contrario, se los debe disuadir de practicar un deporte de competición, que en todo caso debe ser autorizado por el cardiólogo. Los pacientes con insuficiencia cardíaca o cianosis requieren períodos de sueño y descanso más frecuentes y prolongados que los de un niño sano de su edad. Los niños con insuficiencia cardíaca suelen tener ortopnea, por lo que duermen mejor semisentados.

\section{Riesgos de las enfermedades intercurrentes ${ }^{14}$}

Para evaluar el posible riesgo de una enfermedad intercurrente, los principios fisiopatológicos esenciales son:

1. Los cortocircuitos de izquierda a derecha (por ejemplo, en la comunicación interventricular) aumentan (llega más sangre al pulmón y menos a la aorta) cuando suben las resistencias sistémicas o bajan las pulmonares; sucede lo contrario en los cortocircuitos de derecha a izquierda (por ejemplo, en la tetralogía de Fallot).

2. Las obstrucciones a la salida del ventrículo empeoran con la taquicardia porque disminuye el tiempo de eyección.

Las cuatro situaciones de riesgo más comunes y los cambios fisiopatológicos que ocurren o pueden ocurrir en ellas son:
1. Fiebre: taquicardia, taquipnea, vasoconstricción periférica en el pico febril seguida de vasodilatación, y aumento del consumo de oxígeno.

2. Deshidratación: taquicardia, hipotensión, hemoconcentración, alteración electrolítica (resulta de especial riesgo la hipopotasemia, que favorece la intoxicación por digitálicos) y acidosis metabólica.

3. Infección broncopulmonar: taquipnea, hipoxemia e hipercapnia (que aumenta las resistencias pulmonares). Además, suele haber fiebre y puede que también cierta deshidratación. La causa más común de empeoramiento de un lactante con insuficiencia cardíaca o cianosis es la bronquiolitis por virus respiratorio sincitial (ver acerca de su prevención a continuación).

4. Apneas obstructivas: hipercapnia.

Las cardiopatías leves no se descompensan en absoluto. A mayor gravedad, mayor riesgo de descompensación.

\section{Control y riesgos de la medicación cardiológica}

En primer lugar, el pediatra debe comprobar que las dosis administradas de su medicación cardiológica son las prescritas en el alta hospitalaria. Evolutivamente, como en cualquier enfermo crónico, hay que vigilar la adherencia. 
Los riesgos de la medicación dependen del propio medicamento y de factores externos, como la deshidratación y los desequilibrios electrolíticos o las interferencias entre fármacos. Debemos tener a mano la ficha técnica de cada fármaco para poder realizar consultas rápidas. En las figuras 4 y 5 se resumen los riesgos fundamentales de los dos más clásicos (furosemida y digoxina).

\section{Riesgos de la medicación no cardiológica}

En cuanto al tratamiento de las enfermedades intercurrentes, los medicamentos de uso común con mayor riesgo son los simpaticomiméticos utilizados como vasoconstrictores nasales (orales o tópicos), que además tienen una escasa utilidad terapéutica, por lo que no deben utilizarse en niños con cardiopatías significativas o con taquiarritmias. Otros fármacos con efectos simpaticomiméticos, como los broncodilatadores agonistas $\beta_{2}$, se usan en dosis habituales cuando son necesarios, pero es preciso conocer que podrían precipitar taquiarritmias en pacientes sensibles. En altas dosis, los agonistas $\beta_{2}$ pueden ocasionar hipopotasemia (los corticoides también).

\section{Vacunaciones y prevención} de la infección por virus respiratorio sincitial ${ }^{14-16}$

Los lactantes con cardiopatías leves deben vacunarse según el calendario habitual. Si bien con calendarios distintos, en todas las comunidades españolas se vacuna durante la lactancia frente

Figura 4. Riesgos de la furosemida.

Pérdida de agua, $\mathrm{K}, \mathrm{Na}, \mathrm{Mg}$ (deshidratación, apatía, arritmias)

- Si vómitos o diarrea: suspender hasta mejoría

Ototoxicidad

- Evitar aminoglucósidos

Potencia efecto de fármacos hipotensores

- Al inicio controlar TA

Con hidrato de cloral puede dar lugar a una reacción peculiar: rubor, calor, sudor, taquicardia e hipertensión 
a la difteria, el tétanos y la tos ferina (actualmente se usa sólo tos ferina atenuada, que ocasiona menos efectos secundarios), la poliomielitis (actualmente se usa sólo la vacuna inyectable de virus inactivos, no la oral de virus vivos atenuados), la hepatitis $B$, el hemofilus $b$, el meningococo C y sarampión, rubeola y parotiditis (aunque las hay por separado, en el calendario de todas las comunidades se ponen siempre juntas; esta vacuna se denomina triple vírica).

Los niños que padecen una cardiopatía significativa deberían vacunarse además frente a la gripe, el neumococo y la varicela:

- Por el momento, la vacuna antigripal no está en el calendario habitual de ninguna comunidad, pero puede administrarse a los niños mayores de 6 meses gratuitamente por ser un grupo de riesgo.

- La vacuna frente al neumococo puede ser conjugada con proteínas (que estimulan los linfocitos $T$, dejando memoria) o de polisacáridos capsulares (que sólo estimula los linfocitos $B$, de forma que la inmunidad dura lo que duren los anticuerpos). La primera se puede poner a partir de los 2 meses, pero la segunda no es eficaz hasta los 2 años. La conjugada actual es heptavalente, aunque en breve se dispondrá de otras con más serotipos, y sólo está incluida en el calendario madrileño. En las demás comunidades puede administrarse gratuitamente por pertenecer a un grupo de riesgo. Los que

Figura 5. Riesgos de la digoxina

\section{Impregnación}

- Discreto aumento del PR, disminución de la FC, disminución del QT y depresión ST en cubeta

\section{Intoxicación}

1. Arritmias: Bradicardia sinusual intensa, extasístoles ventriculares politópicos, $B A V 2^{\circ}$ grado, fibrilación auricular, etc.

2. Síntomas (tardíos): anorexia, nauseas, diarrea, cefalea, parestesias

La toxicidad aumenta si:

- Hipopotasemia

- Otros: Hipoxia, hipomagnesemia, hipocalcemia 
tienen una cardiopatía grave, aunque hayan sido vacunados con una vacuna conjugada en la lactancia, deberían revacunarse a partir de los 2 años con una vacuna antineumocócica de polisacáridos (la actual es 23-valente). La segunda dosis de 23-valente se pone a los 3 años de la primera en menores de 10 años. En mayores de esta edad, o a partir de la segunda dosis en menores, el intervalo de revacunación con 23-valente es cada 5 años.

- La vacuna frente a la varicela se administra a partir de los 12 meses. En Madrid, Navarra y Melilla forma parte del calendario a los 15 meses. En otras comunidades o no se vacuna, o sólo se administra a los adolescentes que no hayan pasado la varicela, pero en todas ellas los cardiópatas pueden vacunarse gratuitamente a partir del año como grupo de riesgo usando cualquiera de las dos marcas comerciales disponibles en España.

Aunque desconocemos si existen aún estudios en niños con cardiopatías, parece razonable aconsejar que se vacunen también frente a rotavirus, ya que esta vacunación se propone para toda la población. Por el momento no se incluye en ninguna comunidad ni de manera rutinaria ni, que sepa, como grupo de riesgo.

Puesto que por ahora no se dispone de una vacuna frente al virus respiratorio sincitial, los lactantes con cardiopatías graves pueden recibir inmunización pasiva con un anticuerpo específico (palivizumab). Se administra una dosis intramuscular mensual sólo en hospitales. No presenta ninguna interacción con ninguna vacuna.

Las inyecciones intramusculares están contraindicadas en niños que toman anticoagulantes orales. En estos casos, las vacunas se inyectan en tejido subcutáneo y se comprime después 2 minutos, sin masajear.

En el siguiente apartado se realizan algunas consideraciones sobre las vacunas en el período pre y posoperatorio de las cardiopatías congénitas.

\section{Cuidados pediátricos preoperatorios}

Es aconsejable que los lactantes que van a ser operados no vayan a la guardería, ni a lugares cerrados y concurridos, quizá en las 2 semanas previas a la cirugía. Esto es especialmente importante durante las epidemias invernales de virus respiratorio sincitial.

El lavado de manos es una medida preventiva de primer orden para evitar el contagio de múltiples bacterias y vi- 
rus, no sólo de aquellos cuya transmisión es fecal-oral, con una excepción notable: es poco eficaz en la prevención de la gastroenteritis por rotavirus, lo que es un dato a favor de la recomendación de la vacuna. También hay que limpiar los fonendoscopios, las batas y otros objetos que toquen a los niños, ya que pueden ser transmisores de virus y bacterias (especialmente en hospitales, donde es probable que sean resistentes a antibióticos).

Los niños mayores que van a operarse pueden ser revisados uno o dos meses antes por el odontólogo a fin de tratar sus posibles caries antes del período de máximo riesgo de endocarditis, que ocurre tras la cirugía.

Con respecto a las vacunas, en el preoperatorio podrían tomarse las siguientes precauciones ${ }^{14,16}$ :

1. Tras las vacunas de virus vivos atenuados (polio oral, sarampión, rubeola, parotiditis, rotavirus y varicela), el vacunado puede padecer una enfermedad atenuada tras un período de incubación de 1 a 4 semanas (según el virus). También elimina virus durante varias semanas. Se ha demostrado contagio con la vacuna oral de poliomielitis (que ya no se usa en España) pero no con la triple vírica, y es excepcional pero posible con varicela y con rotavirus.
2. Tras la vacuna del sarampión se ha descrito muy rara vez (3 ó 4 casos por 100.000 dosis) trombocitopenia, que puede durar varios meses y suponer un problema durante la cirugía cardíaca con circulación extracorpórea. También se ha descrito tras la vacuna contra la varicela.

En resumen, para evitar riesgos innecesarios es mejor no administrar las vacunas frente a rotavirus en el mes previo a la cirugía; asimismo, las de sarampión (o triple vírica) y varicela pueden retrasarse en aquellos pacientes que tengan prevista cirugía poco después de la edad habitual de vacunación.

\section{Cuidados pediátricos posoperatorios}

Tras el alta es poco probable que aparezca alguna complicación importante. Una de las posibles es la fiebre. Ésta puede deberse a causas comunes, pero también a infecciones quirúrgicas (de la heri$\mathrm{da}$, del mediastino o del endocardio), o al síndrome pospericardiotomía. La infección de la herida puede ocurrir hasta 6-8 semanas tras la cirugía. Tiene buen pronóstico si es superficial, pero es muy grave si afecta al esternón y el mediastino. Hay que diferenciarla de los pequeños enrojecimientos e infecciones alrededor de puntos subcutáneos que, en vez de reabsorberse, son expulsados (este proceso puede tardar 1-3 meses). El síndro- 
me pospericardiotomía es una pleuropericarditis aséptica que cursa con fiebre y dolor retroesternal. Ocurre generalmente 1 ó 2 semanas después de la cirugía. Es excepcional en lactantes, pero su frecuencia aumenta con la edad. Suele ser una enfermedad moderada y autolimita$\mathrm{da}$, pero excepcionalmente hay derrames pericárdicos tan intensos que ocasionan taponamiento cardíaco.

Las vacunas de virus atenuados, y en menor medida las de microorganismos inactivos y subunidades, pueden resultar menos eficaces si el paciente necesitó durante la cirugía transfusiones de derivados sanguíneos que contienen anticuerpos. Cuando se usa sangre completa o plasma, la respuesta puede atenuarse varios meses. No es ninguna contraindicación, pero dependiendo del caso se podrían repetir más adelante las vacunas que fueron puestas en ese período.

\section{Profilaxis de endocarditis y prevención de las caries}

Las lesiones endoteliares del corazón o los vasos ocasionan trombos locales que pueden infectarse a partir de bacterias $u$ hongos del torrente sanguíneo (endocarditis, endarteritis, flebitis). Las endocarditis en niños sin cardiopatía ni otros factores de riesgo (como catéteres venosos centrales) son posibles pero poco frecuentes (menos del 10\%). Dentro de las cardiopatías congénitas, las de mayor riesgo de endocarditis son la tetralogía de Fallot, la comunicación interventricular y la estenosis aórtica. En el extremo opuesto, de muy bajo riesgo, están la estenosis pulmonar leve, el prolapso mitral sin insuficiencia mitral y la comunicación interauricular tipo ostium secundum. Tras la cirugía cardíaca o el cierre de algunos cortocircuitos con dispositivos colocados mediante cateterismo, el riesgo de endocarditis es también variable, desde un máximo en las válvulas protésicas hasta un mínimo tras la corrección quirúrgica o por cateterismo de la comunicación interauricular, interventricular y conducto arterioso.

La base teórica de la profilaxis de endocarditis puede resumirse así: cuando se lesionan y sangran los endotelios o epitelios colonizados por bacterias saprofitas, éstas pueden pasar al torrente sanguíneo dando lugar a pequeñas bacteriemias, que podrían infectar con mayor facilidad un endocardio dañado que uno sano. Si se administra un antibiótico al que habitualmente es sensible la bacteria prevista, el riesgo debería reducirse o desaparecer. Clásicamente se ha recomendado profilaxis antibiótica ante procedimientos dentales o quirúrgicos con riesgo de bacteriemia en todas las car- 
diopatías menos en la comunicación interauricular tipo ostium secundum. También se aconsejaba profilaxis en los 6 meses posteriores a la cirugía o colocación de dispositivos de cierre mediante cateterismo, período en el cual se supone que el material de sutura o cierre se habrá epitelizado. Sin embargo, aunque la base teórica resulta convincente, la utilidad real parece baja y puede ser menor que los riesgos del antibiótico, por lo que está siendo cada vez más cuestionada: mientras en 2004 la guía de la Sociedad Europea de Cardiología mantenía unos consejos similares a los mencionados, en 2007 la Asociación Americana del Corazón restringió notablemente su uso y en 2008 el Instituto Nacional para la Salud y Excelencia Clínica ${ }^{17}$ del Reino Unido desaconsejó la profilaxis de endocarditis sin excepciones. Parece pues que la mejor forma de evitar la endocarditis es simplemente la prevención primaria de las caries ${ }^{18}$.

\section{Secuelas y apoyo psicológico}

La malnutrición y el retraso de crecimiento en países como el nuestro quedan limitados a un pequeño grupo de cardiopatías congénitas complejas que no han podido corregirse de forma satisfactoria o a cardiopatías adquiridas graves. Los niños con cardiopatías congénitas graves suelen tener una lactancia tormentosa que puede retrasar los hitos habituales del desarrollo psicomotor (sentarse, andar, hablar), pero la mayoría se recupera y sólo unos pocos quedan con alguna secuela neurológica importante (retraso mental, parálisis, sordera, convulsiones). Los factores determinantes de las secuelas neurológicas son la gravedad de la hipoxemia originada por su cardiopatía y, en un grado muy inferior, las técnicas quirúrgicas complejas a las que son sometidos $^{19}$. La escoliosis es más frecuente en adolescentes que fueron sometidos a toracotomía para cirugía cardíaca. No son infrecuentes los trastornos psicológicos y el retraso escolar, de causa multifactorial.

El pediatra de cabecera, el enfermero e incluso el personal administrativo del centro de salud pueden ayudar mucho a los niños con enfermedades crónicas graves de cualquier tipo y a sus familias. También existen asociaciones de ayuda mutua en varias zonas de España (por ejemplo, en Madrid tenemos Menudos Corazones: www.menudoscorazones.org/).

\section{Coexistencia de síndromes} malformativos. Riesgo de recurrencia. Prevención de las cardiopatías congénitas

Algunas cardiopatías congénitas forman parte de una cromosomopatía o 
síndrome malformativo ${ }^{20}$. El pediatra de AP debe prestar especial atención a la presencia de dismorfias, ya que algunos síndromes pasan desapercibidos en el período neonatal (por ejemplo, los de Turner, Marfán o Williams-Beuren).

El riesgo de recurrencia cuando un progenitor o un hermano tienen una cardiopatía congénita siempre es mayor que en la población general, pero aún así es bastante bajo (1-15\%, según cardiopatías y series). No sólo tienen un componente hereditario las malformaciones, sino también las miocardiopatías y algunas arritmias (por ejemplo, la mio- cardiopatía hipertrófica y el síndrome de QT largo sin sordera son autosómicos dominantes).

Las embarazadas deben tomar suplementos de ácido fólico, que no sólo previene defectos del tubo neural, sino también cardiopatías congénitas ${ }^{21}$. Si la madre o alguno de sus hijos tienen una cardiopatía congénita de gravedad, puede realizarse un control ecocardiográfico fetal entre las semanas 16 y 20. En esa edad de gestación es posible detectar una malformación cardíaca grave y ofrecer a los padres la posibilidad de abortar.

\section{Bibliografía}

1. Arias López I, Martínez Tallo E, Campo Sampedro F, Cardesa García JJ. Incidencia de las cardiopatías congénitas en la provincia de Badajoz. An Pediatr (Barc). 2008;69:23-7

2. Hoffman JI, Kaplan S. The incidence of congenital heart disease. J Am Coll Cardiol. 2002; 39:1890-900.

3. Wren C, O'Sullivan JJ. Survival with congenital heart disease and need for follow up in adult life. Heart. 2001;85:438-43.

4. Young PC, Shyr Y, Schork MA. The role of the primary care physician in the care of children with serious heart disease. Pediatrics. 1994; 94 : 284-90.

5. Martí Henneberg C. Crecimiento y nutrición en las cardiopatías congénitas. En: Sánchez PA, ed. Cardiología pediátrica. Clínica y cirugía. Madrid: Salvat; 1986. p. 1095-102.

6. Varan B, Tokel K, Yilmaz G. Malnutrition and growth failure in cyanotic and acyanotic congenital heart disease with and without pulmonary hypertension. Arch Dis Child. 1999; 81:49-52.

7. Moreno Villares JM, Oliveros Leal L, Sánchez Díaz I, Pérez Pérez A, Galletti L. Estado nutricional de lactantes afectados por una cardiopatía congénita compleja antes de la cirugía. Acta Pediatr Esp. 2007;65:24-8.

8. Ardura Fernández J, González Herrera C, Aragón García MP. Factores hemodinámicos y retraso de crecimiento en operados de comunicación interauricular. An Pediatr. 2003;58:302-8.

9. Marino BL, O'Brien P, Lo Re H. Oxygen saturations during breast and bottle feeding in in- 
fants with congenital heart disease. J Pediatr Nurs. 1995;10:360-4.

10. Beneítez Maestre AM, Moreno Villares JM. Suplementos nutricionales. En: Muñoz Calvo MT, Suárez Cortina L. Manual práctico de nutrición en pediatría. Madrid: Ergon; 2007. p. 22133 [consultado el 18/12/2009]. Disponible en www.aeped.es/nutricion/manual2007.htm

11. Olcay L, Ozer S, Gurgey A, Saraclar M, Ozme S, Bilgic A, Ozkutlu S, Celiker A. Parameters of iron deficiency in children with cyanotic congenital heart disease. Pediatr Cardiol. 1996; 17:150-4.

12. Horwich TB, Fonarow GC, Hamilton MA, MacLellan WR, Borenstein J. Anemia is associated with worse symptoms, greater impairment in functional capacity and a significant increase in mortality in patients with advanced heart failure. J Am Coll Cardiol. 2002;39:1780-6.

13. Baño Rodrigo A, Martos Moreno G. Ejercicio físico y deporte en niños cardiópatas. En: Sociedad Española de Cardiología Pediátrica y Cardiopatías Congénitas. Protocolos diagnósticos y terapéuticos en Cardiología Pediátrica [consultado el 18/12/2009]. Disponible en www.secar dioped.org

14. Smith P. Primary care in children with congenital heart disease. J Pediatr Nurs. 2001; 16 : 308-19.

15. Gómez Campderá JA. Vacunaciones en niños con enfermedades crónicas. En: Asociación Española de Pediatría. Manual de vacunaciones en pediatría 2005. p. 735-41 [consultado el 18/12/ 2009]. Disponible en www.vacunasaep.org/ma nual/12.pdf

16. Plotkin $S A$, Orenstein W. Vaccines, fourth edition. New York: Elsevier; 2004.

17. National Institute for Health and Clinical Excellence. Prophylaxis against infective endocarditis: antimicrobial prophylaxis against infective endocarditis in adults and children undergoing interventional procedures. NICE clinical guideline 64. March 2008.

18. Vitoria Miñana I, De Baturell Castillo A. Promoción de la salud bucodental. En: Recomendaciones Previnfad/PAPPS [consultado el 18/12 /2009]. Disponible en www.aepap.org/previn fad/Dental.htm

19. Limperopoulos C, Majnemer A, Shevell MI, Rosenblatt B, Rohlicek C, Tchervenkov C. Neurologic Status of newborns with congenital heart defects before open heart surgery. Pediatrics. 2006;103:402-8.

20. Moreno García M, Gómez Rodríguez MJ, Barreiro Miranda E. Genética de las cardiopatías congénitas. An Esp Pediatr. 2000;53:30-9.

21. Jenkins KJ, Correa A, Feinstein JA. Noninherited risk factors and congenital cardiovascular defects: current knowledge. A scientific statement from the American Heart Association council on cardiovascular disease in the young. Endorsed by American Academy of Pediatrics. Circulation. 2007;115:2995-3014. 